\title{
Evacuation Simulation System Considering Evacuee Profiles and Spatial Characteristics
}

\section{SHIGEO UEHARA}

Research and Development Institute, TAKENAKA CORPORATION

1-5-1, Ohtsuka, Inzai, Chiba, 270-1395, Japan

E-mail: uehara.shigeo@takenaka.co.jp

\section{KEIKO TOMOMATSU}

OR and CSRP Division, KOZO KEIKAKU ENGINEERING INC.

4-5-3, Chuo, Nakano-Ku, Tokyo, 164-0011, Japan

E-mail: tomomatu@kke.co.jp

\begin{abstract}
In considering the issue of safety during emergency building evacuations, it is important to be able to make accurate predictions about evacuation conditions and to be able to assess safety levels. Simulation techniques are often used to make predictions regarding evacuation conditions. The two main types of prediction models are crowd flow models and discrete models. We have developed an evacuation simulation system based on the discrete model, which attempts to address the implementation problems of crowd flow model. Our model incorporates characteristics such as evacuee profiles and spatial considerations, and is capable of dynamically predicting the behavior of individual evacuees. The simulation system is primarily designed for buildings in which many people are incapacitated and require helpers in order to evacuate, such as hospitals and facilities for the elderly. We show the results that the evacuation simulation system was used to perform two trial simulations.
\end{abstract}

KEYWORDS: Evacuation, Simulation, Fire, Evacuee profiles, Spatial characteristics

\section{INTRODUCTION}

In considering the issue of safety during emergency building evacuations, it is important to be able to make accurate predictions about evacuation conditions and to be able to assess safety levels. Simulation techniques are often used to make predictions regarding evacuation conditions. In general, there are two main types of prediction models.

(1) A crowd flow model that estimates evacuation time from walking time along the evacuation route and time required for groups to pass through bottlenecks along the evacuation route, such as doors

(2) A discrete model for modeling individual evacuees and predicting the overall evacuation state from their movement in relation to spatial considerations

The crowd flow model provides hypothetical conditions that are simple and comprehensible and can predict the time required for evacuation and the maximum 
number of people waiting in front of the exit doors relatively easily from formulas and graphs. Hence, this model is widely used in Japan for assessing evacuation safety in the Building Fire Prevention Plan.[1] However, this model is not suitable for incorporating evacuee profiles and spatial considerations in the prediction of evacuation conditions, since evacuation is modeled as a uniform group flow.

The discrete model on the other hand models the behavior of individual evacuees and, unlike the crowd flow model, is capable of predicting in great detail the evacuation conditions over time and the spatial movement of evacuees. While several simulation models have already been proposed in Japan, there is a great amount of freedom in the method of modeling used, since the software for generating those models each has its own individuality. Hence, specialized knowledge and much effort are required for programming and simulating using such programs.

We believe it will be necessary to predict evacuation with greater detail in the future due to an influx of building designs aimed at disaster prevention, a diversity of evacuees resulting from the progressive aging of society, and an increasing complexity of building spaces. We have developed an evacuation simulation system based on the discrete model that attempts to address implementation problems of existing evacuation models in Japan. Our system incorporates evacuee profiles and spatial considerations in the discrete model and is capable of dynamically verifying the behavior of individual evacuees. A versatile discrete simulator, CAD software, spreadsheet program and animation program was used to construct of our simulation system. (See Fig. 1)

The simulation system considers hospitals and facilities for the elderly in which many people are incapacitated and require the assistance of attendants in order to evacuate during a disaster and incorporates this model in the simulation. The system can predict the overall evacuation conditions in which there is a combination of both incapacitated and able evacuees. In this paper, we provide the results of trial demonstrations using this simulator.



Fig. 1 Construction of evacuation simulation system 


\section{SIMULATION MODEL CONSIDERING EVACUEE PROFILES AND SPATIAL CHARACTERISTICS}

\subsection{Spatial Model and Route Settings}

The entire evacuation area targeted for simulation is divided into a grid pattern comprised of blocks(Fig.1-2), where a block signifies the smallest area that evacuees go through during the simulation. Evacuees move from block to adjacent block in the direction of evacuation, although there may be more than one directional setting at any given block, depending on the attributes of the evacuee. The evacuation routes are modeled by setting orders of precedence. Evacuation is conducted according to these settings, while considering which routes are passable based on the evacuees' attributes and congestion in the path.


Fig.1-2 Illustration of blocks

\subsection{Evacuee Model}

The simulation system allows the setting of multiple types of evacuees, each having attributes for floor area occupied per person and walking speed according to crowd density. Evacuees move from their current position to successive blocks along an evacuation direction set for each block. Fig. 2 shows a basic model of this movement. A new direction is sought when a block having highest order of precedence has exceeded its allowable density. When unable to move in any direction, the evacuee waits in the current block, advancing only when there is an opening in the next block. The user has the freedom to set the initial position, evacuation start time, and walking speed for each evacuee. Part A in Fig. 3 shows a flowchart of the overall simulation.



Fig. 2 Basic evacuation simulation model 




Fig. 3 Flowchart of the simulation process

\section{SIMULATION MODEL CONSIDERING EVACUATION CHARACTERISTICS AT HOSPITALS OR OTHER FACILITIES WITH INCAPACITATED INHABITANTS}

\subsection{Evacuation Characteristics of the Building Inhabitants}

Hospitals and other facilities with incapacitated people have evacuation characteristics different from other facilities.

(1) Many inhabitants cannot evacuate under their own power.

(2) The evacuating speed of people who can move unaided also tends to be slower than normal.

(3) People who have difficulty moving unaided are evacuated with the assistance of attendants, such as nurses.

(4) Methods of assisted evacuation include locking arms with the evacuee or carrying the evacuee on one's back, and often include the use of such equipment as stretchers and wheelchairs, depending on the condition of the person being helped.

(5) The speed of evacuation and time required for assisted evacuation differs according to the method of assistance and number of attendants.

(6) A single floor is divided into multiple fire compartments. Evacuees in the compartment which fire breaks evacuate temporarily to a neighboring compartment and subsequently evacuate to the stairs (to be called as horizontal evacuation method). 


\subsection{Evacuees and Attendants}

Evacuees can be set to one of three types with different behaviors: self-reliant evacuees, incapacitated evacuees (those who have difficulty evacuating under their own power), and attendants.

(1) Self-reliant evacuees

These evacuees can move independently without the help of others and are modeled in the same way as the evacuees described in section $\mathbf{2 . 2}$.

(2) Incapacitated evacuees

These evacuees cannot move under their own power and must wait for attendants to arrive and evacuate under their assistance. Since there are various methods of aided evacuation corresponding to the physical condition of the evacuee, the number of attendants required and the method of assisted evacuation (locking arms with the evacuee, using a stretcher, wheelchair, or the like) are set for each evacuee. Based on these differences, the time required for assistance, evacuation speed, and area of floor space occupied during evacuation can be set separately for each type of incapacitated evacuee. Evacuees requiring two attendants cannot begin evacuation until two attendants have arrived.

(3) Attendants

Attendants who help others can also move independently the same as self-reliant evacuees. Their speed and area of floor space occupied when going to aid another can be specified. These attendants repeatedly aid others

Evacuation Start


Figures in this chart indicate the priority of evacuee.


Fig. 4 Modeling of assisted evacuation until all incapacitated evacuees have been evacuated. When aiding others, the evacuation speed of attendants is the same as incapacitated evacuees. 


\subsection{Attendant Route Settings}

When attendants move to assist an evacuee, the shortest path is calculated from the attendant's current position to the hospital room of the incapacitated evacuee and the attendant follows that route.

\subsection{Attendant Zone Settings}

Attendants are normally pre-assigned to specific zones, such as fire compartments or nursing units in hospital wards, as is the priority for assisted evacuation in case of an actual emergency. Each floor can be divided into a desired number of areas with each attendant assigned to specific areas. The assigned areas can also be assigned priority levels. Attendants repeatedly perform assisted evacuations in their area beginning at the highest priority level.

\subsection{Assistance Priority Settings}

A priority for evacuation is sometimes given to incapacitated evacuees based on their physical and mental conditions. Therefore, we have made it possible to set assistance priorities indicating the priority of evacuation for each incapacitated evacuee. Attendants evacuate those people in their assigned zone in order from highest assistance priority. Order of precedence is set automatically for evacuees having the same priority.

\subsection{Sharing Assistance during Evacuation}

In the horizontal evacuation method, incapacitated evacuees in the compartment breaking fire are all temporarily moved to a neighboring compartment and subsequently moved to the final evacuation area. In such a case, attendants can temporarily leave evacuees during the evacuation and the other attendants take over the assisted evacuation process. The overall simulation flow is shown in Fig. 3 and these modeling are shown in Fig. 4.

\section{SIMULATIONS FOR BUILDINGS HAVING SPECIAL SPATIAL CHARACTERISTICS}

Evacuation simulation was conducted for a theater. The theater is a one-floor auditorium with 408 seats fixed to the floor. Evacuation routes are configured using a limited number of paths. Settings for the arrangement of evacuees and starting time of evacuation were studied in simulations that considered a mix of two types of evacuees having different evacuation capabilities. The floor space was divided into approximately 760 blocks.

\subsection{Seating Arrangement and Evacuation Routes}

An aisle running horizontally across the auditorium divides the seats into nine front rows and eight back rows. Two aisles run lengthwise through the seats, dividing each row into six seats on the left and right and twelve in the center. An additional aisle is provided 
around the entire seating section. There are four exits from the auditorium, as shown in Fig. 5. Evacuees move to an aisle on the left or right from their seats and proceed from the lengthwise aisle to a horizontal aisle and out through an exit. Those evacuees entering the corridor through rear exits 3 and 4 proceed toward the stair 3, while those leaving through front exits 1 and 2 proceed toward stairs 1 and 2 , respectively. When there is congestion on the way to stairs 1 and 2, however, those evacuees can also proceed toward stair 3. Assuming all seats in the auditorium are filled, the number of evacuees would be 408 .



Fig. 5 Simulating theater plan and evacuation routes

\subsection{Characteristics of the Evacuees}

Evacuation capability is represented by walking speed. As shown in Table 1, two types of evacuees were established: fast walkers and slow walkers. The floor space occupied per person on the evacuation route was set the same for both types. The maximum allowable density on the evacuation route was set to 6.0 people $/ \mathrm{m}^{2}$ for the flat aisle portions, 5.0 people $/ \mathrm{m}^{2}$ for the sloped portions, and 4.0 people $/ \mathrm{m}^{2}$ for the stair portions.

Table 1 Walking speed of evacuees

\begin{tabular}{l|l|l}
\hline Density & Type 1 evacuees & Type 2 evacuees \\
\hline \hline Less than 2 people/m2 & $2.0 \mathrm{~m} / \mathrm{sec}$ & $0.5 \mathrm{~m} / \mathrm{sec}$ \\
\hline 2-3 people $/ \mathrm{m} 2$ & $1.5 \mathrm{~m} / \mathrm{sec}$ & $0.375 \mathrm{~m} / \mathrm{sec}$ \\
\hline 3-4 people $/ \mathrm{m} 2$ & $1.0 \mathrm{~m} / \mathrm{sec}$ & $0.25 \mathrm{~m} / \mathrm{sec}$ \\
\hline More than 4 people $/ \mathrm{m} 2$ & $0.75 \mathrm{~m} / \mathrm{sec}$ & $0.189 \mathrm{~m} / \mathrm{sec}$ \\
\hline
\end{tabular}

Note: We assume that the walking speed of Type 1 evacuees(fast walkers) is twice and Type 2 evacuees(slow walkers) is half as fast as ordinary to confirm the quality of simulation system. 


\subsection{Simulated Cases}

Five cases were simulated as shown in Table 2. In most cases, the mixed ratio of the two evacuee types was set at $50 \%$ while varying the initial arrangement and evacuation start time.

Table 2 Simulated Cases

\begin{tabular}{l|l|l}
\hline Case & Type 1 evacuees & Type 2 evacuees \\
\hline \hline 1 & $408(100 \%)$ & 0 \\
\hline 2 & $204(50 \%)$ & $204(50 \%)$ \\
& $\begin{array}{l}\text { Evacuees seated at 12 seats by 17 rows } \\
\text { in the center, farthest from the exits; } \\
\text { simultaneous evacuation }\end{array}$ & $\begin{array}{l}\text { Evacuees seated at 6 seats by 17 rows } \\
\text { on the left and right, nearest the exits; } \\
\text { simultaneous evacuation }\end{array}$ \\
\hline 3 & $\begin{array}{l}204(50 \%) \\
\text { Evacuees seated randomly; } \\
\text { simultaneous evacuation }\end{array}$ & $\begin{array}{l}\text { 204(50\%) } \\
\text { Evacuees seated randomly; } \\
\text { simultaneous evacuation }\end{array}$ \\
\hline 4 & $\begin{array}{l}\text { S04(50\%) same seating arrangement as case 2; } \\
\text { evacuation begun 30 seconds after } \\
\text { type 2 evacuees start }\end{array}$ & $\begin{array}{l}\text { 204(50\%) } \\
\text { Same seating arrangement as case 2; } \\
\text { evacuation begun before type } \\
\text { evacuees }\end{array}$ \\
\hline \multirow{2}{*}{5} & $\begin{array}{l}\text { Same seating arrangement as case 2; } 50 \%) \\
\text { evacuation begun before type } \\
\text { evacuees } 204(50 \%) \\
\text { Same seating arrangement as case 2; } \\
\text { evacuation begun 30 seconds after } \\
\text { type 1 evacuees start }\end{array}$ \\
\hline
\end{tabular}

\subsection{Simulation Results}

The findings confirmed that slower evacuees affect the faster evacuees' evacuation time when located near the exits (see cases 2 and 3 in Fig. 6). It was also found that a more efficient evacuation process could be conducted without the effects of congestion by setting appropriate evacuation start times for people of different evacuation capabilities (see cases 5 in Fig. 6).



Fig. 6 Evacuation state from auditorium to corridor (all exits) 
By simulating a single floor in a hospital (see Fig. 7) having a total of eighteen hospital rooms and thirty-nine evacuees (five self-reliant and thirty-four incapacitated), we studied the effects on the evacuation process of varying the number of attendants and the method of assisted evacuation. The evacuation characteristics set for the evacuees and attendants are shown in Table 3.



Table 3 Number and Characteristics of evacuees and attendants [2]

\begin{tabular}{|l|c|c|c|c|}
\hline & \multirow{2}{*}{$\begin{array}{c}\text { Number of } \\
\text { evacuees }\end{array}$} & \multicolumn{2}{|c|}{ Speed of evacuation } & $\begin{array}{c}\text { Setup time of } \\
\text { evacuation } \\
\text { (sec) }\end{array}$ \\
\cline { 3 - 4 } & & $\begin{array}{c}\text { Floor } \\
(\mathrm{m} / \mathrm{sec})\end{array}$ & $\begin{array}{c}\text { Stairway } \\
(\mathrm{m} / \mathrm{sec})\end{array}$ & - \\
\hline \hline Self-reliant evacuee (patient) & 5 & 0.5 & 0.25 & 20 \\
\hline Evacuee in wheelchair(1 attendant) & 6 & 2.2 & 0.2 & 10 \\
\hline Evacuee in wheelchair(2 attendants) & 6 & 2.5 & 0.26 & 15 \\
\hline Evacuee on stretcher(1 attendant) & 6 & 1.3 & 0.2 & 10 \\
\hline Evacuee on stretcher(2 attendants) & 6 & 1.8 & 0.26 & 8 \\
\hline Evacuee led by arm(1 attendant) & 5 & 0.9 & 0.2 & 8 \\
\hline Evacuee led by arm(2 attendants) & 5 & 1.8 & 0.26 & - \\
\hline Attendant & 420 & 2.0 & 1.0 & - \\
\hline
\end{tabular}

\subsection{Case 1: Modifying the Number of Attendants}

Simulations were conducted while setting the number of attendants to $4,6,8,10,12$, and 20. The method of assistance was as follows.

This method of assisted evacuation consisted of temporarily moving incapacitated inhabitants on the floor to the stairway and subsequently evacuating them via the stairway.

Incapacitated evacuees were assisted in order based on pre-assigned priorities. 
A floor area was divided into three zones by fire compartment. A study was conducted on the horizontal evacuation method in which people were evacuated beginning from zones nearest the outbreak of fire. The following is a description of the assisted evacuation method conducted in the simulation.

1. First, incapacitated evacuees in the center zone are evacuated to the adjacent zone on the right.

2. When all people are evacuated from the center zone, incapacitated evacuees in the zone on the right are moved to the stairway.

3. Evacuation via the stairs is conducted after all people are assembled in front of the stairway.

The number of attendants was set at ten. Case 2-1 is six attendants go to the center zone at first, and case 2-2 is all ten attendants go to the center zone at first. The above method was compared with the assisted evacuation method conducted in case 1 .

\subsection{Simulation Results}

Findings confirmed that evacuation completion time improved when increasing the number of attendants. Hence, we learned that the operations of attendants are an important factor in addition to the overall layout of the building (see Fig. 8). We also determined that overall evacuation times from zones nearest the fire could be cut in half by performing horizontal evacuation and deemed that the horizontal evacuation method is effective (see Fig. 9).



Fig. 8 Time required to reach the evacuation area based on the type of evacuee 
Case 1

Single-stage evacuation with ten attendants to

evacuation area zoned off by a fire door

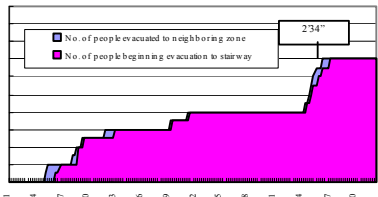

Single-stage evacuation with ten attendants to

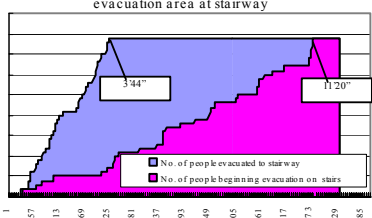

Case 2-1

Horizontal evacuation with ten attendants(6:4) to evacuation area zoned off by a fire doo

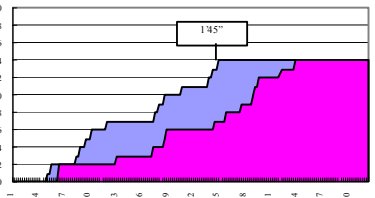

Horizontal evacuation with ten attendants( $6: 4)$ to

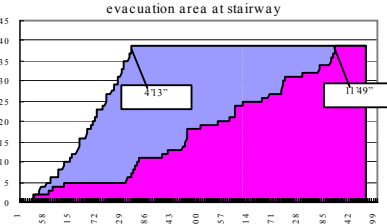

Case 2-2

Horizontal evacuation $w$ ith ten attendants $(10: 4)$ to evacuation area zoned off by a fire door

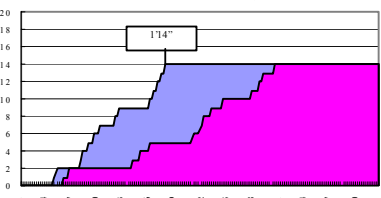

Horizontal evacuation $w$ ith ten attendants( $10: 0)$ to evacuation a rea at stairway

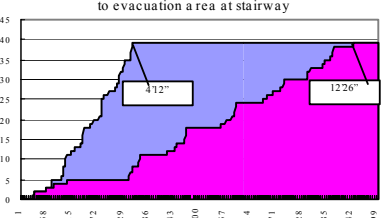

Fig. 9 Evacuation time based on method of evacuation

26 seconds
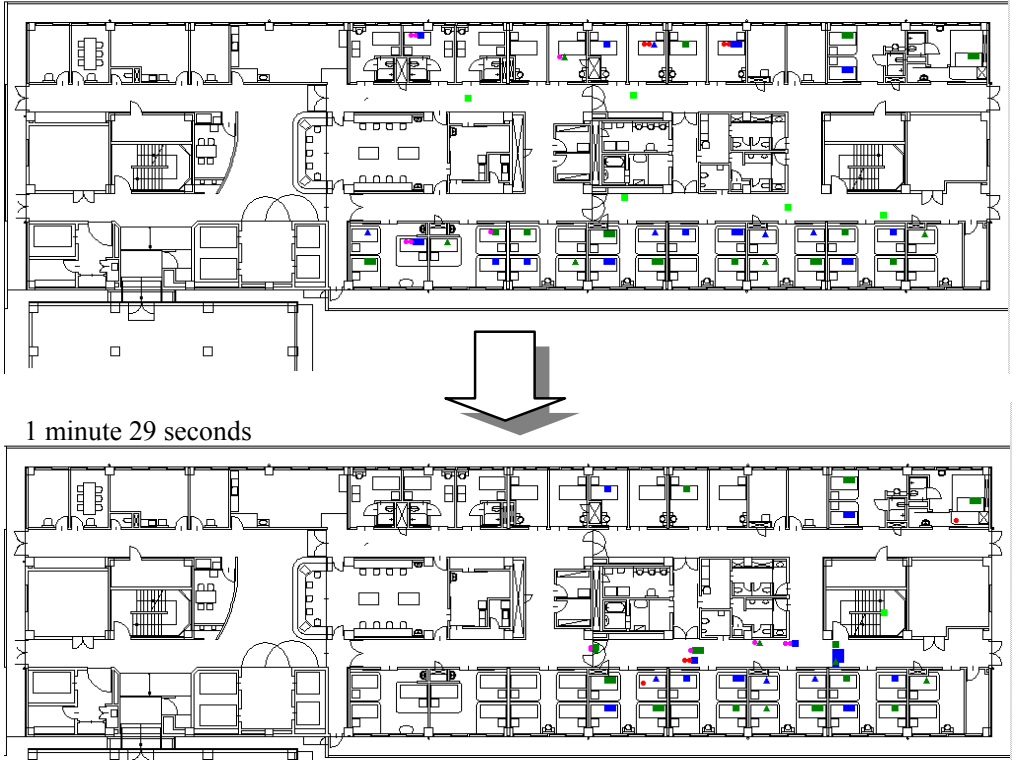

4 minutes 16 seconds


Fig.10 Simulation result, the state of evacuation (Case 2-1) 


\section{CONCLUSION}

The above paper describes evacuation simulations capable of dynamically predicting the behavior of individual evacuees and evacuation simulations that also consider assisted evacuation. We also reported on example applications of this evacuation simulation. It is difficult to reproduce evacuation conditions using static calculations when evacuees having different capacities are mixed in buildings with complex evacuation routes, such as theaters, and in cases where attendants assist people who cannot evacuate under their own power. These cases depend in large part on performing simulations dynamically. In the future, we hope to develop the simulations to study a broader range of conditions by incorporating predictions of fire behavior.

\section{REFERENCES}

[1] The building center of Japan, "Building Fire Safety Design Guide", 1995 (Japanese)

[2] Kazuyoshi Ohnishi, Masuteru Murozaki, Mamiko Kujime, "A Study on Hospital Evacuation Planning, No.2 Quantitative Analysis of Patient Evacuation Behavioral Ability", Proceedings of the Annual Convention of the Architectural Institute of Japan, Hokkaido, 1986 (Japanese) 